\title{
Clinical Profile of Patients with Psoriasis and their Attitude Towards the IIIness
}

\author{
Authors: \\ *Padmavathi Nagarajan, ${ }^{1}$ Devinder Mohan Thappa ${ }^{2}$ \\ 1. Jawaharlal Institute of Post Graduate Medical Education and Research (JIPMER), \\ Puducherry, India \\ 2. North Eastern Indira Gandhi Regional Institute of Health and Medical Sciences \\ (NEIGRIHMS), Shillong, Meghalaya, India \\ *Correspondence to padmavathi2002@gmail.com \\ Disclosure: The authors have declared no conflicts of interest. \\ Received: $\quad 03.10 .19$ \\ Accepted: $\quad 09.12 .19$ \\ Keywords: $\quad$ Attitude towards psoriasis, clinical profile, psoriasis, Psoriasis Attitude Assessment \\ Questionnaire (PSAQ). \\ Citation: \\ EMJ. 2020;5[1]:79-85.
}

\section{Abstract}

Introduction: Psoriasis is a chronic inflammatory hyperproliferative disease of the skin and affects 0.6-4.8\% of the world's population. In addition to the skin and joint manifestations, psoriasis impairs many aspects of individual wellbeing, including emotional, physical, sexual, and financial status. Skin diseases such as psoriasis can profoundly influence a patient's self-image, self-esteem, and sense of wellbeing. This study aimed to assess the clinical profile of patients with psoriasis and their attitude towards living with the disease.

Methods: A cross-sectional descriptive design was used. Two hundred subjects diagnosed with psoriasis were recruited through purposive sampling. A structured proforma was used to assess the clinical profile and attitude was assessed by Psoriasis Attitude Assessment Questionnaire (PSAQ).

Results: The most common type of psoriasis was chronic stable psoriasis (86.5\%). A family history of psoriasis was present in 30 (15.0\%) subjects. Stress was attributed to the exacerbation of disease in 90 (45.0\%) subjects. Itching was reported by 124 (62.0\%) subjects, and sleep disturbance was reported by 85 (42.5\%) of the subjects. The majority of individuals (n: 187; 93.5\%) had a moderately favourable attitude towards living with psoriasis.

Conclusion: Living with psoriasis can be difficult for patients because of the inconvenience caused by the disease in their daily life. Knowledge about the pathogenesis and treatment of psoriasis may increase the patient's perception of control and attention to aggravating factors may increase patient's compliance with treatment and positive lifestyle habits.

\section{INTRODUCTION}

Skin diseases such as psoriasis can profoundly influence a patient's self-image, self-esteem, and sense of wellbeing. The chronic nature of the disease, as well as the fact that it cannot

be cured and requires continuous treatment, generates frustration and disappointment in affected patients. The disturbances in body image perception contribute to the overall morbidity in psoriasis. Psoriasis requires lifetime treatment, but this is often difficult and 
unsatisfactory. Patients with psoriasis directly experience the ineffectiveness of treatments by the inherent visibility of any recurrence. Findings from the National Psoriasis Foundation (NPF) and European Federation of Psoriasis Patients Associations (EUROPSO) ${ }^{2}$ surveys showed that respondents felt psoriasis had a negative impact on their lives. Embarrassment, shame, impaired self-image, low self-esteem, self-consciousness, and stigmatisation were more prominent among psoriasis patients compared to the general population. ${ }^{3}$ Despair and feelings of stigmatisation may lead to noncompliance with treatment, possibly worsening the disease. ${ }^{4}$

The literature reviewed by Rabin et al. ${ }^{5}$ revealed that patients with psoriasis felt shame and embarrassment over their appearance. According to Linder et al., ${ }^{6}$ the disease was often seen by patients as incomprehensible, incurable, and uncontrollable. ${ }^{6}$ The visibility of the skin lesions and the social stigma associated with psoriasis results in anger, inconvenience, and frustration among patients with psoriasis. Hence, this study aimed to investigate the clinical profile of patients with psoriasis and their attitude towards the disease, each of whom attended dermatologic outpatient care services of a tertiary care hospital.

\section{METHODS}

Before commencing the study, approval was obtained from the Institute Ethics Committee (IEC) for human studies at the Jawaharlal Institute of Post Graduate Medical Education and Research (JIPMER), Pudhucherry, south India, a tertiary care government hospital where the study was conducted. Participants signed the written informed consent after the risks and benefits of the study were explained. Privacy was provided and confidentiality was maintained throughout the study. The study was based on self-report, after providing confidentiality of the disclosure.

A cross-sectional, descriptive design was used that included 200 subjects diagnosed with psoriasis attending the outpatient department of dermatology at JIPMER. Adult subjects of either sex aged between 18 and 65 years, and with body surface area (BSA) involvement $>10 \%$, were recruited as samples by purposive sampling technique. Data collection was done through face-to-face interview.

\section{Brief Description of Tools Used}

The clinical profile consisted of details such as duration of illness, presenting complaints, medical history, previous hospitalisation, family history, personal history, and clinical diagnosis. A Psoriasis Attitude Assessment Questionnaire (PSAQ) was developed for the study, which consisted of 20 items. Content validity of the tool was established in consultation with the experts from the dermatology, psychiatry, and psychology departments of the JIPMER and other reputed institutions. The final instrument was translated into Tamil, and the Tamil translation was retranslated to English for validity of the translated version. The attitude was assessed by five-point Likert scaling method, with the responses ranging from 'strongly disagree' to 'strongly agree'. Test-retest methodology was used to assess the reliability of this instrument. The ' $r$ ' value was 0.70 and found to be reliable.

\section{RESULTS}

\section{Clinical Profile of the Study Subjects}

The disease was chronic in 157 (78.5\%) subjects and exacerbated in 32 (16.0\%) subjects. Among the 200 subjects, 92 (46.0\%) were treated as inpatients up to six times. Disease onset most commonly occurred when subjects were aged between 21 and 30 years ( $\mathrm{n}$ : 55; 27.5\%), followed by $31-40$ years in 52 (26.0\%) subjects. In respect to the duration of the current episode of illness, 153 (76.5\%) subjects reported it to be $<3$ months. The details of the clinical profile of the subjects are documented in Table 1.

The distribution of the subjects based on other clinical variables is documented in Table 2. Out of 200 subjects, 123 (61.5\%) had the illness for $<10$ years, 71 (35.5\%) subjects had the illness ranging from 10 to 30 years, and six (3.0\%) subjects had psoriasis for $>30$ years. One hundred and fortyfive $(72.5 \%)$ subjects had flare-ups of the disease $<10$ times and 13 (6.5\%) experienced them ranging from 11 to 20 times. Clinical severity, which was based on BSA involvement, showed that 122 (61.0\%) subjects had $20-40 \%$ BSA involvement, whereas 60 (30.0\%) subjects had >40\% BSA involvement. 
Table 1: The clinical profile of the subjects.

\begin{tabular}{|l|l|l|l|}
\hline Variables & Categories & $\begin{array}{l}\text { Number of subjects } \\
(\mathbf{N}: \text { 200) }\end{array}$ & Percentage (\%) \\
\hline \multirow{4}{*}{ Nature of illness } & Chronic & 157 & 78.5 \\
\cline { 2 - 4 } & Exacerbation & 32 & 16.0 \\
\cline { 2 - 4 } & Acute & 6 & 23.0 \\
\cline { 2 - 4 } & Relapsing & 5 & 2.5 \\
\hline \multirow{5}{*}{ Age of onset of illness } & $10-20$ years & 40 & 20.0 \\
\cline { 2 - 4 } & $21-30$ years & 55 & 27.5 \\
\cline { 2 - 4 } & $31-40$ years & 52 & 26.0 \\
\cline { 2 - 4 } & $41-50$ years & 32 & 16.0 \\
\cline { 2 - 4 } & $51-60$ years & 17 & 8.5 \\
\cline { 2 - 4 } & $61-65$ years & 4 & 2.0 \\
\hline \multirow{4}{*}{$\begin{array}{l}\text { Duration of present episode } \\
\text { Type of medical services }\end{array}$} & $1-3$ months & 153 & 76.5 \\
\cline { 2 - 4 } & $>3$ months & 47 & 23.5 \\
\cline { 2 - 4 } & Outpatient & 104 & 52.0 \\
\cline { 2 - 4 } & Hospitalised 1-6 times & 92 & 46.0 \\
\hline
\end{tabular}

Table 2: The clinical profile of subjects based on other clinical variables.

\begin{tabular}{|c|c|c|c|}
\hline Clinical variables & Categories & $\begin{array}{l}\text { Number of subjects } \\
(\mathrm{N}=200)\end{array}$ & Percentage (\%) \\
\hline \multirow[t]{3}{*}{ Total duration of illness } & $1-10$ years & 123 & 61.5 \\
\hline & $11-30$ years & 71 & 35.5 \\
\hline & $>30$ years & 6 & 3.0 \\
\hline \multirow[t]{3}{*}{ Previous flare ups } & No flare ups & 42 & 21.0 \\
\hline & 1-10 times & 145 & 72.5 \\
\hline & $11-20$ times & 13 & 6.5 \\
\hline \multirow{3}{*}{$\begin{array}{l}\text { Clinical severity as assessed } \\
\text { by body surface area }\end{array}$} & $10-20 \%$ & 18 & 9.0 \\
\hline & $21-40 \%$ & 122 & 61.0 \\
\hline & $>40 \%$ & 60 & 30.0 \\
\hline \multirow[t]{5}{*}{ Precipitating factor } & Stress & 90 & 45.0 \\
\hline & Unknown & 46 & 23.0 \\
\hline & Infection & 39 & 19.5 \\
\hline & Drugs & 22 & 11.0 \\
\hline & Alternative medicine & 3 & 1.5 \\
\hline
\end{tabular}


Table 3: Item-wise responses for psoriasis attitude assessment questionnaire.

\begin{tabular}{|c|c|c|c|c|c|c|}
\hline & & Strongly disagree & Disagree & Uncertain & Agree & Strongly agree \\
\hline 1 & $\begin{array}{l}\text { Psoriasis does not interfere } \\
\text { with my daily activities. }\end{array}$ & 30 & 121 & 0 & 42 & 7 \\
\hline 2 & $\begin{array}{l}\text { Others think that my skin } \\
\text { condition is contagious and } \\
\text { do not like to touch me. }\end{array}$ & 10 & 47 & 18 & 118 & 7 \\
\hline 3 & $\begin{array}{l}\text { There is a lot which I can do } \\
\text { to control my symptoms. }\end{array}$ & 2 & 13 & 13 & 153 & 19 \\
\hline 4 & $\begin{array}{l}\text { In spite of having psoriasis, I } \\
\text { am happy. }\end{array}$ & 17 & 121 & 1 & 60 & 1 \\
\hline 5 & $\begin{array}{l}\text { It is difficult to adujst with } \\
\text { application of ointments. }\end{array}$ & 4 & 113 & 5 & 71 & 7 \\
\hline 6 & $\begin{array}{l}\text { I would like to talk to my } \\
\text { friends about my disease. }\end{array}$ & 2 & 34 & 1 & 156 & 7 \\
\hline 7 & $\begin{array}{l}\text { I feel that I am a person } \\
\text { of worth at least equal to } \\
\text { others. }\end{array}$ & 7 & 91 & 4 & 83 & 15 \\
\hline 8 & $\begin{array}{l}\text { I am satisfied with the } \\
\text { medical care I receive. }\end{array}$ & 1 & 13 & 5 & 170 & 11 \\
\hline 9 & $\begin{array}{l}\text { I feel inferior because of my } \\
\text { psoriasis. }\end{array}$ & 5 & 73 & 1 & 117 & 4 \\
\hline 10 & $\begin{array}{l}\text { The medicines I take/ } \\
\text { ointments I use can usally } \\
\text { control my symptoms. }\end{array}$ & 0 & 5 & 29 & 157 & 9 \\
\hline 11 & $\begin{array}{l}\text { I become physically } \\
\text { unattractive when my } \\
\text { psoriasis is bad. }\end{array}$ & 1 & 12 & 14 & 168 & 5 \\
\hline 12 & $\begin{array}{l}\text { Living with psoriasis is hard } \\
\text { for me. }\end{array}$ & 4 & 37 & 0 & 139 & 20 \\
\hline 13 & $\begin{array}{l}\text { I fear that my child also } \\
\text { might get psoriasis. }\end{array}$ & 14 & 76 & 12 & 81 & 17 \\
\hline 14 & $\begin{array}{l}\text { I have difficulty in finding } \\
\text { a job because of my skin } \\
\text { condition. }\end{array}$ & 13 & 91 & 5 & 78 & 13 \\
\hline 15 & $\begin{array}{l}\text { I prefer to have a physician } \\
\text { of the same sex to perform } \\
\text { the physical examination. }\end{array}$ & 3 & 89 & 2 & 97 & 9 \\
\hline 16 & $\begin{array}{l}\text { When lesion-free, I live with } \\
\text { a constant fear of relapse. }\end{array}$ & 12 & 51 & 1 & 118 & 18 \\
\hline 17 & $\begin{array}{l}\text { My family supports me in all } \\
\text { the ways to cope with my } \\
\text { illness. }\end{array}$ & 3 & 10 & 1 & 179 & 7 \\
\hline 18 & $\begin{array}{l}\text { My friends/co-workers avoid } \\
\text { me because of my psoriasis. }\end{array}$ & 18 & 116 & 3 & 54 & 9 \\
\hline 19 & $\begin{array}{l}\text { I have difficulty in managing } \\
\text { financial issues related } \\
\text { to psoriasis treatment } \\
\text { (travelling, purchasing of } \\
\text { medicines). }\end{array}$ & 7 & 47 & 0 & 124 & 22 \\
\hline 20 & $\begin{array}{l}\text { I am uncomfortable to visit } \\
\text { other people's houses, when } \\
\text { my psoriasis is bad. }\end{array}$ & 2 & 8 & 1 & 171 & 18 \\
\hline
\end{tabular}


Furthermore, the findings showed that 90 (45.0\%) subjects attributed the exacerbation of the disease to a preceding episode of a stressful event, 39 (19.5\%) of them had exacerbation followed by infection, and 22 (11.0\%) subjects had exacerbation as a result of the intake of various pharmaceuticals.

The most common type of psoriasis was chronic stable psoriasis (86.5\%). Psoriatic erythroderma was present in $4.0 \%$ of the subjects, palmoplantar psoriasis in $3.0 \%$, scalp psoriasis and unstable psoriasis in $2.5 \%$, and pustular psoriasis in a very small number (1.5\%). The study results revealed higher mean scores towards negative attitude in patients with pustular psoriasis $(43.33 \pm 0.58)$ and unstable psoriasis $(42.60 \pm 5.51)$ when compared to other types of psoriasis. In addition, patients also had physical symptoms such as itching (62.0\%), joint pain (34.0\%), cosmetic disfigurement as a result of the visibility of the disease (50.0\%), and photosensitivity (52.5\%). Furthermore, sleep was disturbed in 85 (42.5\%) subjects, and appetite was reduced in 52 (26.0\%) subjects.

Regarding the prevalence of addiction, 40 (20.0\%) subjects consumed alcohol, 23 (11.5\%) subjects smoked tobacco, and 29 (14.5\%) of subjects had both tobacco smoking and alcohol consumption habits. Furthermore, a family history of psoriasis was present in 30 (15.0\%) subjects.

\section{PATIENTS' ATTITUDES TOWARDS LIVING WITH PSORIASIS}

The results of the study suggested that the majority (n: 187; 93.5\%) of subjects had a moderately favourable attitude towards living with their disease and 11 (5.5\%) subjects had a less favourable attitude.

Furthermore, item-wise responses of the attitude questionnaire are documented in Table 3. Of the 200 subjects, 113 (56.5\%) said that they had no difficulty in applying ointments; additionally, 170 (85.0\%) subjects expressed that they were satisfied with the medical care they received. Conversely, 171 (85.5\%) subjects expressed that they felt uncomfortable to visit other people's houses when their psoriasis was severe, with 118 (59.0\%) subjects reporting that, because of the unpredictable nature of the disease, they lived with a constant fear of relapse even if there was no lesion present. Furthermore, 118 (59.0\%) subjects expressed that others regarded their condition as if it was contagious and avoided to touch them.

\section{DISCUSSION}

Kostyła et al. ${ }^{7}$ found that patients who have a higher level of illness acceptance demonstrate an overall better mental condition. The intensity of psychopathological symptoms was affected by the duration of illness, other people's attitude to the skin disease, age, and educational level of the patients. ${ }^{7}$

In the present study, family history of the condition was found in 30 (15.00\%) subjects, whereas other studies by Manolache et al. ${ }^{8}$ and Ding et al. ${ }^{9}$ have reported this as $10.65 \%$ and $28.43 \%$, respectively. Other researchers observed that those with early disease onset, i.e., <30 years of age, were more likely to have a positive family history of psoriasis. ${ }^{10,11}$

Itch is a common complaint among patients with psoriasis. Itching and scratching frequently lead to a vicious itch-scratch cycle. Pruritus was reported by $62.0 \%$ of the present study subjects. The similar findings were reported by Gupta et al. ${ }^{12}$ (67.0\%), Fortune et al. ${ }^{13}$ (76.0\%), and Krueger et al. ${ }^{1}$ (79.0\%). Disturbed sleep was reported by $85(42.5 \%)$ subjects which was lower than that of study by Gaikwad et al. ${ }^{14}$ who had reported it at $67.4 \%$. Many authors found that pruritus interfered with sleep quality by increasing nocturnal awakenings. 15,16 Skin and joint manifestations associated with psoriasis and psoriatic arthritis were assessed in terms of joint pain. Joint pain was present in 68 (34.0\%) of the subjects. The present study recorded a higher frequency than that of the study result of $28.8 \%$ reported by Valenzuela et al."

The results of the present study revealed that 105 (52.5\%) of the subjects had photosensitivity. The majority of patients with psoriasis benefit from ultraviolet radiation exposure, but psoriasis can deteriorate on exposure to sunlight in some people. Nalluri et al. ${ }^{17}$ reported a patient with longstanding palmoplantar psoriasis that showed an unusual evolution into photo-aggravated psoriasis. The authors concluded that photosensitivity should be suspected in patients with hand and foot 
psoriasis. ${ }^{17}$ This present study indicated that 90 (45.0\%) subjects attributed the exacerbation of their disease to a preceding episode of a stressful event. In different epidemiological studies, psoriasis was reported to be associated with a stressful life event in 10-90\% of cases. ${ }^{5}$

Many researchers have reported that alcohol misuse is common in patients with moderate to severe psoriasis. Drinking alcohol appears to exacerbate pre-existing disease and continued drinking contributes to patient morbidity through treatment resistance. ${ }^{18-20}$ Chodorowska and Kwiatek $^{21}$ stated that cigarette smoking is an important environmental factor exacerbating the course of the disease and provoking its consecutive relapses. The harmful influence of smoking is connected with the inducing of inflammatory mediators taking part in pathogenic phenomena in the skin of psoriatic patients.

The attitudes among study participants were categorised into three groups based on the scores obtained from the attitude questionnaire. Subjects who scored $<50 \%$ of the total attitude score of 100 were considered as having a less favourable attitude; those who scored between 51 and $75 \%$ were considered as having moderately favourable attitudes, and the subjects who scored $>75 \%$ were considered as having a favourable attitude towards living with their disease. The study results revealed that only two subjects (1\%) had the favourable attitude.

The present study found a significant association between attitude and age. The subjects who were $>40$ years of age reported more favourable attitudes when compared to the subjects who belonged to the age group of 20-30 years. Similar finding was reported by Lin et al. ${ }^{22}$ It is assumed that young adults aged $<30$ years have important life tasks, such as employment and marriage, and are more conscious about their physical appearance; it is viewed by some patients that psoriasis negatively affects their quality of life in all these areas. No sex difference was found.

In a recent study by Pearl et al. ${ }^{23}$ that discussed the stigmatising attitudes toward persons with psoriasis among laypersons and medical students, it is implicated that accurate information is needed to eliminate the myths and misconceptions regarding psoriasis. The authors also suggested that public awareness campaigns and incorporating the importance of educating patients of their illness into the medical curriculum will help in improving the quality of life of people with psoriasis. Moreover, evaluating a patient's perceived stigma towards their illness is also necessary to improve the treatment outcome. ${ }^{24-26}$ The present study has explored the attitudes of patients with psoriasis, which may help in planning some interventions. One limitation of the study, however, was that the results lack generalisation because of the sampling technique used being a non-probability sampling technique.

\section{CONCLUSION}

Visible skin symptoms of psoriasis have a severe psychological impact on quality of life. Today, dermatologic treatment of psoriasis has become increasingly effective and can alleviate physical symptoms, but not cure the disease. Many of the difficulties experienced by patients with psoriasis make demands that outstrip the coping measures of patient and their family or social network. They need sufficient education and support from healthcare providers to manage their condition effectively. It is necessary to evaluate the perceptions and beliefs regarding psoriasis from the general public, healthcare providers, as well as a patient's own anticipated and perceived stigma to reduce the negative impact caused by psoriasis among those affected, in addition to its adverse psychological consequences.

\section{References}

1. Krueger $\mathrm{G}$ et al. The impact of psoriasis on quality of life: results of a 1998 National Psoriasis Foundation patient membership survey. Arch Dermatol. 2001;137(3):280-4.
2. Dubertret $L$ et al. European patient perspectives on the impact psoriasis: the EUROPSO patient membership survey. Br J Dermatol. 2006;55(4):729-36.
3. Magin P et al. The psychological sequelae of psoriasis: results of a qualitative study. Psychol Health Med. 2009;14(2):150-61. 
4. Ginsburg IH, Link BG. Feelings of stigmatization in patients with psoriasis. J Am Acad Dermatol. 1989;20(1):53-63.

5. Rabin F et al. Psychiatric and psychological comorbidities in patients with psoriasis- a review. Mymensingh Med J. 2012;21(4):780-6.

6. Linder $\mathrm{D}$ et al. Perception of disease and doctor-patient relationship experienced by patients with psoriasis: a questionnaire-based study. Am J Clin Dermatol. 2009;10(5):325-30.

7. Kostyła $\mathrm{M}$ et al. Illness acceptance degree versus intensity of psychopathological symptoms in patients with psoriasis. Postepy Dermatol Alergol. 2013;30(3):134-9.

8. Manolache $L$ et al. Life events involvement in psoriasis onset/ recurrence. Int J Dermatol. 2010;49(6):636-41.

9. Ding $X$ et al. Prevalence of psoriasis in China: a population-based study in six cities. Eur J Dermatol. 2012:22(5):663-7.

10. Melski JW, Stern RS. The separation of susceptibility to psoriasis from age at onset. J Investigative Dermatol. 1981;77(6):474-7.

11. Valenzuela $\mathrm{F}$ et al. Epidemiology and quality of life of patients with psoriasis in Chile. Actas DermoSifiliográficas. 2011;102(10):810-6.
12. Gupta MA, Gupta AK. The Psoriasis Life Stress Inventory: a preliminary index of psoriasis-related stress. Acta Dermato Venereologica. 1995;75(3):240-3.

13. Fortune DG et al. Quality of life in patients with psoriasis: the contribution of clinical variables and psoriasis-specific stress. $\mathrm{Br} \mathrm{J}$ Dermatol. 1997:137(5):755-60.

14. Gaikwad R, Warren J. The role of home-based information and communications technology interventions in chronic disease management: a systematic literature review. Health Informatics. 2009;15(2):122-46

15. Callis Duffin $\mathrm{K}$ et al. Psoriatic arthritis is a strong predictor of sleep interference in patients with psoriasis. J Am Acad Dermatol. 2009;60(4):604-8.

16. Gowda $S$ et al. Factors affecting sleep quality in patients with psoriasis. $J$ Am Acad Dermatol. 2010;63(1):114-23.

17. Nalluri $R$ et ak. Photoaggravated hand and foot psoriasis. Photodermatol Photoimmunol Photomed. 2010;26(5):261-2.

18. Naldi L et al. Family history, smoking habits, alcohol consumption and risk of psoriasis. $\mathrm{Br} \mathrm{J}$ Dermatol. 1992;127(3):212-7.

19. Naldi L et al. Cigarette smoking, body mass index, and stressful life events as risk factors for psoriasis: results from an Italian case-control study. J Invest Dermatol. 2005;125(1):61-7.

20. Naldi $L$ et al. Association of earlystage psoriasis with smoking and male alcohol consumption: evidence from an Italian case-control study. Arch Dermatol. 1999;135(12):1479-84

21. Chodorowska G, Kwiatek J. Psoriasis and cigarette smoking. Ann Univ Maria Curie Sklodowska Med. 2004;59(2):535-8.

22. Lin TY et al. Quality of life in patients with psoriasis in northern Taiwan. Chang Gung Med J. 2011;34(2):186-96.

23. Pearl RL et al. Stigmatizing attitudes toward persons with psoriasis among laypersons and medical students. J Am Acad Dermatol. 2019;80(6):155663.

24. Vardy $D$ et al. Experiences of stigmatization play a role in mediating the impact of disease severity on quality of life in psoriasis patients. Br J Dermatol. 2002;147(4):736-42

25. Richards $\mathrm{H}$ et al. The contribution of perceptions of stigmatisation to disability in patients with psoriasis. $J$ Psychosom Res. 2001;50(1):11-5.

26. Schmid-Ott $\mathrm{G}$ et al. Quality of life in patients with psoriasis and psoriasis arthritis with a special focus on stigmatization experiences. Clin Dermatol. 2007;25(6):547-54 